\title{
Seismic constraints on dynamic links between geomorphic processes and routing of sediment in a steep mountain catchment
}

\author{
A. Burtin ${ }^{1}$, N. Hovius ${ }^{1}$, B. W. McArdell ${ }^{2}$, J. M. Turowski ${ }^{1}$, and J. Vergne ${ }^{3}$ \\ ${ }^{1}$ GeoForschungsZentrum, Helmholtz Centre Potsdam, Potsdam, Germany \\ ${ }^{2}$ Swiss Federal Institute for Forest, Snow and Landscape Research WSL, Birmensdorf, Switzerland \\ ${ }^{3}$ École et Observatoire des Sciences de la Terre, CNRS UMR7516, Strasbourg, France \\ Correspondence to: A. Burtin (burtin@gfz-potsdam.de)
}

Received: 30 October 2013 - Published in Earth Surf. Dynam. Discuss.: 15 November 2013

Revised: 7 January 2014 - Accepted: 13 January 2014 - Published: 23 January 2014

\begin{abstract}
Landscape dynamics are determined by interactions amongst geomorphic processes. These interactions allow the effects of tectonic, climatic and seismic perturbations to propagate across topographic domains, and permit the impacts of geomorphic process events to radiate from their point of origin. Visual remote sensing and in situ observations do not fully resolve the spatiotemporal patterns of surface processes in a landscape. As a result, the mechanisms and scales of geomorphic connectivity are poorly understood. Because many surface processes emit seismic signals, seismology can determine their type, location and timing with a resolution that reveals the operation of integral landscapes. Using seismic records, we show how hillslopes and channels in an Alpine catchment are interconnected to produce evolving, sediment-laden flows. This is done for a convective storm, which triggered a sequence of hillslope processes and debris flows. We observe the evolution of these process events and explore the operation of two-way links between mass wasting and channel processes, which are fundamental to the dynamics of most erosional landscapes. We also track the characteristics and propagation of flows along the debris flow channel, relating changes of observed energy to the deposition/mobilization of sediments, and using the spectral content of debris flow seismic signals to qualitatively infer sediment characteristics and channel abrasion potential. This seismological approach can help to test theoretical concepts of landscape dynamics and yield understanding of the nature and efficiency of links between individual geomorphic processes, which is required to accurately model landscape dynamics under changing tectonic or climatic conditions and to anticipate the natural hazard risk associated with specific meteorological events.
\end{abstract}

\section{Introduction}

Geomorphic processes seldom occur in isolation. Instead, multiple processes acting on different parts of the landscape tend to occur together, in linked, two-way fashion during geomorphic events. The nature and efficiency of these interactions determines landscape response to external forcing. Hillslopes and channels in active landscapes are coupled through the effects of sediment transfer (Whipple, 2004). Hillslope processes supply sediment to streams (Hovius et al., 2000), which use it to carve their channel beds (Sklar and Dietrich,
2001; Attal and Lavé, 2006; Turowski et al., 2007; Cook et al., 2013). Channel erosion, in turn, can undercut hillslopes and cause further slope erosion (Densmore et al., 1997). This two-way link between channels and slopes permits the tectonic deformation of river long profiles (Burbank et al., 1996; Snyder et al., 2000; Attal et al., 2008) and climatic forcing to affect erosion on adjacent hillslopes (Korup et al., 2010). Similarly, the impact of climate on mass wasting can propagate downward into the fluvial system (Page et al., 1994; Wobus et al., 2010), adjusting the balance of river sediment load and transport capacity and associated channel dynamics 
(Hartshorn et al., 2002; Stark et al., 2010). Even on the scale of an individual rainstorm, the transfer of sediment from hillslopes to channels and the effects of the resultant flow on the surrounding topography can propagate the impact of localized erosion to locations far outside its original footprint.

Despite their fundamental importance to the dynamics of landscapes, observational constraints on the links between geomorphic processes and the progress of eroded material are scarce (Yanites et al., 2011) because remote sensing and in situ monitoring of geomorphic activity do not have the required resolution. Remotely sensed imagery has a spatial resolution at the metre-scale (Hervas et al., 2003; Lin et al., 2004; Saba et al., 2010) but a temporal resolution that depends on the timing of overhead passage and also on cloud cover. This is not sufficient to constrain the way in which individual processes are linked in a single geomorphic event. In contrast, ground-based monitoring that includes in situ observations provides the required temporal characteristics but tends to have a spatial extent that does not cover geomorphic process systems in their entirety (Itakura et al., 2005; McArdell et al., 2007). For example, downstream, in-channel monitoring can yield frequent and localized measurements of flow properties that result from the integration of various upstream processes, but does not generally allow for this signal to be deconvolved in order to establish the pattern of geomorphic activity in the contributing catchment. To improve constraints on landscape dynamics at the catchment scale, it is, therefore, required to have observations with a sufficient spatial resolution to determine where individual geomorphic processes occur and a high temporal resolution constraining the timing of their occurrence as well as their interplay.

Seismological data have the potential to enhance highresolution surveys of landscape dynamics. Like any environmental process, geomorphic activity displacing mass along the Earth's surface produces ground vibrations that are recorded at distant seismometers (Govi et al., 1993; Brodsky et al., 1999; Burtin et al., 2009; Lacroix et al., 2012). Seismic instruments operate with a high sampling rate, giving data coverage, potentially for years, at high temporal resolution. Moreover, with several sensors, the respective timing of seismic signals at individual stations allows the location of geomorphic sources. Finally, the amplitude and frequency characteristics of seismic signals allow the identification of individual processes (Huang et al., 2007; Burtin et al., 2013).

Thus, where background seismic noise is weak relative to the geomorphic signal, seismic records can be used to resolve erosion and sediment transport with useful spatiotemporal detail. Such an approach has been used to study incidents of landslide motion (Deparis et al., 2008; Favreau et al., 2010), rock avalanches (Dammeier et al., 2011), debris flow (Itakura et al., 2005; Arattano and Marchi, 2008; Badoux et al., 2009) and bedload transport (Burtin et al., 2010, 2011; Hsu et al., 2011). However, these studies have not typically considered the interplay of different geomorphic processes at the landscape scale. With a two-dimensional network of

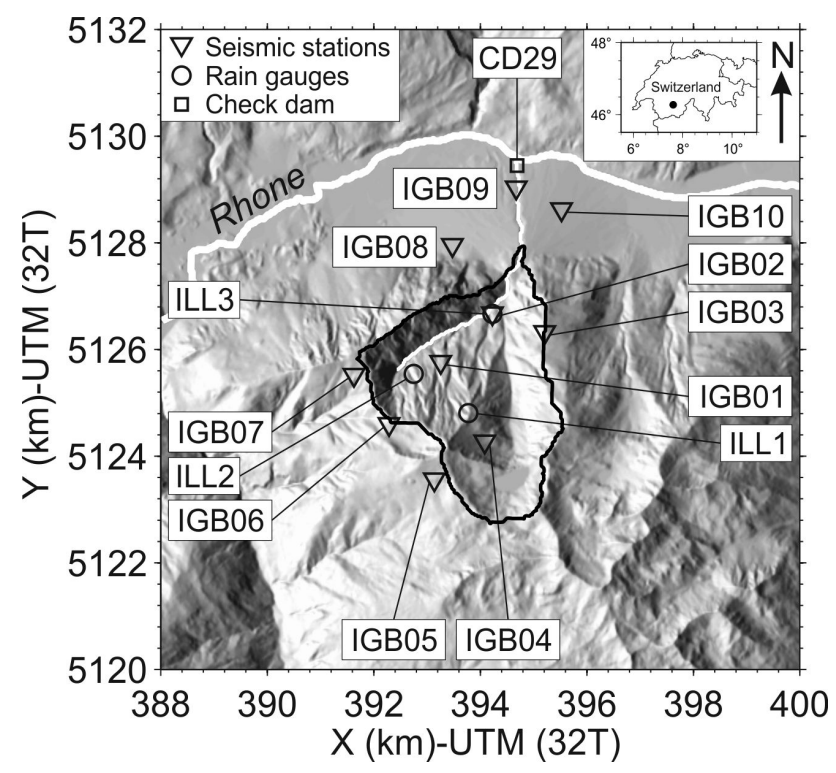

Figure 1. The Illgraben catchment. Location of the Illgraben catchment $\left(\sim 10 \mathrm{~km}^{2}\right.$, outlined in black) in Switzerland (dot in the inset map) and of the seismological stations deployed there during summer 2011 (inverse triangles, labelled IGBnn), meteorological stations from the Swiss Federal Institute for Forest, Snow and Landscape Research WSL (circles, labelled ILLn), and check dam 29 (CD29, square) where the flow depth and bedload impact rates of the study were observed.

seismometers, it is possible to scan for patterns of geomorphic activity across a landscape in continuous mode unlike any existing geomorphic technique (Burtin et al., 2013). We did this in the Illgraben, a steep mountain catchment in the Swiss Alps. With an array of ten instruments it was possible to track sediment moving from hillslopes into and along channels, obtaining constraints on the two-way link that exists between these two topographic domains. In addition, the analysis of seismic records along the main stream of the Illgraben catchment permitted observation of the downstream evolution of flow events arising from headwater erosion.

\section{Experiment settings}

\subsection{Study area}

The Illgraben catchment supplies 5-15\% of the sediment load of the Rhone River (Schlunegger et al., 2012) from a small catchment area of about $10 \mathrm{~km}^{2}$ (Fig. 1). This high yield reflects the large catchment relief of $>2 \mathrm{~km}$ and slopes with an average gradient of $40^{\circ}$ in fractured sedimentary rocks, making the Illgraben extremely prone to mass wasting and debris flows (Schlunegger et al., 2009). Flow events are commonly triggered in summer during convective rainstorms with measured $10 \mathrm{~min}$ rainfall intensities of up to $11.4 \mathrm{~mm}$ (Berger et al., 2011). They occur in a channel with mean 
slope of $16 \%$ in bedrock that connects with the Rhone River across a debris fan with a gradient of $10 \%$ (Badoux et al., 2009).

The channel is equipped with a debris flow monitoring system that uses geophone sensors bolted to three different check dams located inside the catchment. Sediment impacting, rolling or sliding on these check dams activates the geophones and if the recorded impulse rate exceeds a predetermined threshold, an alarm is triggered (Badoux et al., 2009). In addition, flow depth is monitored with laser sensors and sediment impact frequency with force plates at the outlet of the debris fan (CD29, Fig. 1) (McArdell et al., 2007), and flow events are registered by video cameras at this site. The setup is complemented by three automatic weather stations along an elevation transect in the catchment (ILL1-3, Fig. 1). This combination of frequent geomorphic events and existing instrumentation makes the Illgraben a suitable location for development and testing of seismic monitoring of geomorphic processes. For future deployment, seismic monitoring does not require this extreme rate of activity and can be used in locations where surface processes occur at more modest rates. Despite the anomalously high rate of erosion, the simple geomorphic structure, with a single trunk channel flanked by steep, dissected hillslopes, and the commonality of the dominant surface processes in the catchment should make our findings relevant and portable rather than unique. Notably, long-term observation of the Illgraben has given detailed insight into the meteorological preconditions for debris flow occurrence and flow mechanics (Schürch et al., 2011), but understanding of their origin and downstream evolution has remained difficult (Bennett et al., 2013).

\subsection{Seismological data set}

During the summer of 2011, we deployed ten seismometers in and around the Illgraben catchment (labelled IGB01 to IGB10 Fig. 1) in a 2-dimensional (2-D) geometry with an average instrument spacing of $2.88 \mathrm{~km}$. Three stations were placed along the central channel to monitor flow processes, and the remaining seven were located in a ring that surrounded the catchment to record geomorphic activity on hillslopes. With this configuration, we aimed to record the activity on hillslopes and survey the spatiotemporal behaviour of flows in the Illgraben main channel. The seismic instruments were intermediate band Güralp CMG-6TD (IGB01, IGB03 to IGB07), Güralp CMG-40T (IGB02) and short period Lennartz LE-3Dlite (IGB08 to IGB10) seismometers. With the exception of the CMG-40T instrument, which has a flat response in the $[0.033-50] \mathrm{Hz}$ frequency band, all instruments had a flat response in at least the $[1-100] \mathrm{Hz}$ frequency band. This high-frequency band is well suited to the study of geomorphic processes (e.g. Helmstetter and Garambois, 2010; Burtin et al., 2011). The sampling frequency rate was set to 200 samples per second (SPS) for the intermediate band sensors and 125 SPS for the short period instruments.
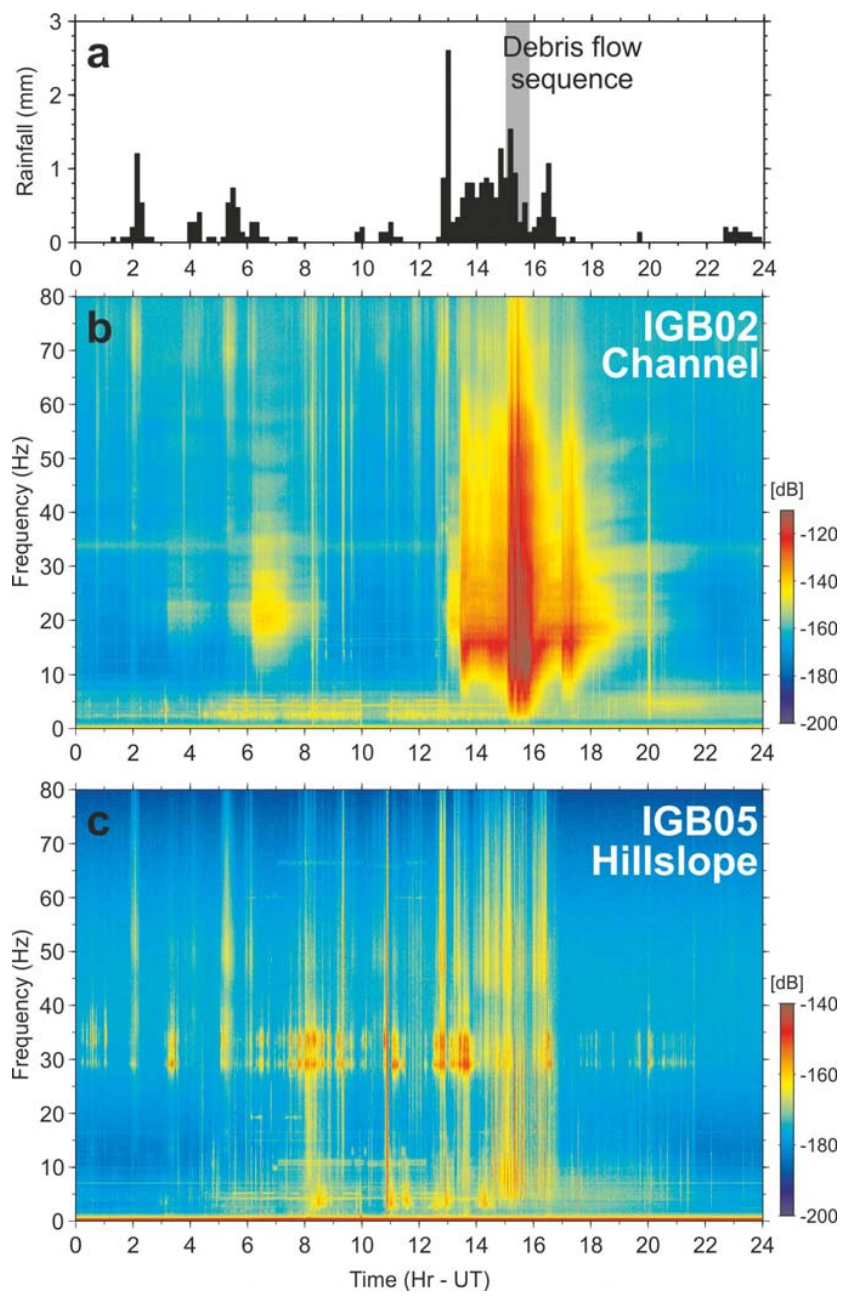

Figure 2. Spectral and temporal characterizations of surface processes. (a) Mean 10 min rainfall intensities recorded in the Illgraben catchment (gauges ILL1-3) on 13 July 2011. The gray shaded interval delineates the occurrence of debris flows. (b-c) Spectrograms for the same time period of the seismic signals recorded at station IGB02, located along the main channel, and station IGB05, outside the catchment. The amplitude is given in decibel relative to the velocity.

The seismic stations recorded for up to 100 days, but here we focus on a single rainstorm on 13 July 2011, which had the largest daily cumulative rainfall of the summer with $27 \mathrm{~mm}$ (Fig. 2a). This storm caused a debris flow that triggered the warning system. The debris flow propagated through the Illgraben catchment and over the debris fan and eventually entered the Rhone River.

\subsection{Rainfall record}

During 13 July 2011, the rainstorm did not show large temporal and spatial variability over the catchment. The correlation coefficients between the three rain gauges ranged from 
0.84 to 0.91 . Therefore, the precipitation rates averaged over these three locations well illustrate the meteorological conditions of this day in the Illgraben catchment. Some precipitation occurred early in the day, preceding a convective rainstorm in the afternoon with $2 / 3$ of the daily rainfall total (Fig. 2a). Compared to historical records for the Illgraben, this convective storm with a total precipitation of $18 \mathrm{~mm}$ was not exceptional; similarly sized rain storms are not uncommon in the catchment during the summer season. Notably, the peak $10 \mathrm{~min}$ rainfall intensity of $2.6 \mathrm{~mm}$, which was observed at the start of the storm, did not result directly in the occurrence of a debris flow. Instead, the debris flow warning system in the Illgraben was triggered in the later part of the storm, when $60 \%(11 \mathrm{~mm})$ of cumulative precipitation had already occurred.

\section{Data processing}

\subsection{Spectral analysis}

A time-frequency analysis of the continuous seismic data shows the main features of seismic signals (e.g. Burtin et al., 2008). Spectrograms were calculated with a power spectral density (PSD) approach. To compute the PSD of a time series, we first detrended the seismic signal, subtracted the mean, and deconvolved the instrument response. Then we used a multitaper method to estimate the power spectrum in one-minute time windows without overlap (Thomson, 1982). This PSD estimate offers a good frequency resolution despite the use of short duration seismic signals, which decrease the number of computed frequencies in a spectrum.

\subsection{Event location method}

Spectrograms of our seismic records show a number of events with durations of no more than a few tens of seconds, high-frequency content, and complex source time functions. These are the principal seismic characteristics of rockfalls (Helmstetter and Garambois, 2010). Such falls constitute well-defined sources of seismic energy, and it should be possible to determine their location. However, locating is made difficult by the high-frequency content and complexities in the source time functions of the signals of rockfalls and other erosion processes, which suppress coherence of waves between stations (Burtin et al., 2009; Lacroix and Helmstetter, 2011). Moreover, it is not possible to consistently identify specific seismic wave types such as body or surface waves in the absence of constraints on the velocity structure of the survey area, precluding the drawing of ray paths in the medium. Nevertheless, the location of hillslope processes can be determined with methods based on crosscorrelation of seismic waveforms or envelops. Two types of approaches exist. One employs the maximization of coherent seismic signals (waveforms or envelops) and is called beamforming method (Almendros et al., 1999; Lacroix and Helm- stetter, 2011). We employed another approach based on probability density function, which is computationally cheaper. It uses the cross-correlation of seismic signals between stations to determine the time delays that give optimally coherent observations across the instrument network (Burtin et al., 2009). Then the migration of these observed time delays, that is, the conversion from time to distance, can be used to retrieve the origin of an event. The cross-correlation of wave packets may include a combination of body and surface waves. For this reason, we preferred the use of a simple ballistic propagation, taking into account the topography in our migration procedure.

Specifically, for $N$ available stations we first detrended the vertical seismic signal, removed the mean and deconvolved the instrument response. Next, we identified the frequency band with the maximum signal-to-noise ratio (SNR) for a given event. This was done by exploring frequencies ranging from 1 to $45 \mathrm{~Hz}$, the dominant frequency band for hillslope processes, with a bandwidth increasing from 0.5 to $10 \mathrm{~Hz}$. The seismic signals were bandpass filtered and we kept the results with the highest average SNR for all stations combined. Prior to computation of time delays in the selected frequency band, we normalized the time series to their maximum amplitude. For a pair of stations with index $i_{1}$ and $i_{2}$, we cross-correlated the seismic recordings and determined the time delay $\mathrm{d} t_{\mathrm{obs}}^{i_{1} i_{2}}$ that corresponds to the maximum amplitude of the correlation function envelope. The time range of exploration should take into account the distance between stations $i_{1}$ and $i_{2}$ with respect to the topography $\mathrm{d} l^{i_{1} i_{2}}$ and the presumed propagation velocity $V$. Therefore, it corresponds to

$\mathrm{d} t_{\mathrm{obs}}^{i_{1} i_{2}} \in\left[-\mathrm{d} l^{i_{1} i_{2}} / V,+\mathrm{d} l^{i_{1} i_{2}} / V\right]$.

With a set of $N(N-1) / 2$ time delays, we implemented a migration step to convert time delays into distances for the event location, using a ballistic propagation (constant velocity) that takes into account the topography of the Illgraben catchment. The ray paths were assumed to follow the surface topography if it is the shortest path, and otherwise to cut through substrate (Fig. S1)

For each grid point $(x, y)$ of the domain, we compared the calculated time delay $\mathrm{d} t_{\text {calc }}$ and the observed time delay $\mathrm{d} t_{\text {obs }}$ for an event source at the surface according to the probability density function

$\rho_{\mathrm{d}}(x, y, V)=\sum_{i_{1}=1}^{N-1} \sum_{i_{2}=i_{1}+1}^{N} e^{\left[-\frac{\left(\mathrm{d} t_{\mathrm{calc}}^{i_{1} i_{2}-\mathrm{d} t_{1} i_{1} i_{2}}\right)^{2}}{2 \sigma_{\mathrm{d} t}(V)^{2}}\right]}$,

where $\sigma_{\mathrm{d} t}(V)$ is the time error. We allowed this parameter to vary with the velocity in order to conserve a constant distance error of $0.2 \mathrm{~km}$. A larger value would give event locations with a large uncertainty, whereas setting a smaller distance error might negatively affect the ability to properly locate an event. Since the propagation velocity is unknown, we explored a wide range of possible values, from $0.2-1.5 \mathrm{~km} \mathrm{~s}^{-1}$, 
for high-frequency seismic waves travelling near the surface. To increase the accuracy of the location method, we introduced an a priori probability density function $\rho_{\mathrm{m}}(x, y)$, which is centred on the location of the station that first recorded the arrival of the event, following the expression

$\rho_{\mathrm{m}}(x, y)=e^{\left[-\frac{\left(x-x_{\text {sta }}^{\text {firs }}\right)^{2}+\left(y-y_{\text {sta }}^{\text {first }}\right)^{2}}{2 \sigma_{\text {prior }}^{2}}\right]}$.

where $x_{\text {sta }}^{\text {first }}$ and $y_{\text {sta }}^{\text {first }}$ are the coordinates of the seismic station, and $\sigma_{\text {prior }}$ is the error on the assumption. This error was set at $1.60 \mathrm{~km}$, the mean value of the inter-station distance of the three nearest stations of the Illgraben array. Hence, the final probability density function $\rho_{\text {final }}(x, y, V)$ is given by the relation

$\rho_{\text {final }}(x, y, V)=\rho_{\mathrm{d}}(x, y, V) \times \rho_{\mathrm{m}}(x, y)$.

We then looked for the maximum amplitude of $\rho_{\text {final }}(x, y, V)$ to retrieve the best propagation velocity $\left(V_{\text {best }}\right)$ and location of the event. To delimit the most likely location, we normalized $\rho_{\text {final }}(x, y, V)$ to the maximum amplitude and kept grid points that exceeded an arbitrary, conservative threshold of 0.75 (note, 0.95 is customary in seismic location methods).

To determine the time delays between seismic stations, we tested two methods based on the cross-correlation of seismic waveforms and seismic envelopes commonly used for landslides and non-volcanic tremors (e.g. Burtin et al., 2009; Zhang et al., 2010). Differences between the use of seismic waveforms and envelopes were generally but not always small. Figure S2 shows the vertical seismic signals at two paired stations (IGB03-IGB04 and IGB01-IGB05) for a rockfall event (rock 1, see Sect. 4) to which we paid particular attention, together with the cross-correlation of seismic waveforms and seismic envelopes. For the station pair IGB03-IGB04, the difference between the two methods was only $0.14 \mathrm{~s}$ (Fig. S2e-f). For the pair IGB01-IGB05 and in the interval $\mathrm{d} t_{\mathrm{obs}}$, which is coherent with the distance between stations and the best fit velocity $\left(0.5 \mathrm{~km} \mathrm{~s}^{-1}\right.$, see Sect. 4$)$, the time difference was $0.42 \mathrm{~s}$ (Fig. S2g-h). A difference of this magnitude has a limited impact on the accuracy of the location. However, the peak of amplitude of the crosscorrelation function from envelopes was not located in the interval $\mathrm{d} t_{\mathrm{obs}}$ of exploration (Eq. 1). It registered instead with a delay of $7.6 \mathrm{~s}$ (Fig. S2h) and was not detectable on the cross-correlation function computed from the seismic waveforms (Fig. S2g). This discrepancy is not problematic since the peak is out of the interval of exploration. However, for ballistic velocities of 0.2 and $0.3 \mathrm{~km} \mathrm{~s}^{-1}$, this peak coincided with the best time delay for the pair IGB01-IGB05. This could give rise to merger or interference with peaks from other station couples and would influence the accuracy of event location. Although such a detailed analysis was not made systematically, we think that the observed behaviour may be representative. Since the use of a cross-correlation of seismic waveforms gave better constraints on the location, we gave preference to this approach rather than the crosscorrelation of seismic envelopes.

\section{Rockfalls and flow pulses}

\subsection{Seismic signals and sources in the Illgraben}

Daily spectrograms for 13 July 2011 at stations IGB02 and IGB05 illustrate the main characteristics of the seismic signal in the Illgraben catchment (Fig. 2). Along the stream, IGB02 recorded episodes of elevated high-frequency seismic energy that are consistent with the occurrence of rainfall. The episode with highest energy recorded at this station coincided with the convective afternoon storm and the ensuing flow sequence, which activated the debris flow detection and warning system of the Illgraben at 17:15 local time. This time coincidence of meteorological events, seismically recorded activity and independent flow detection are initial evidence for a seismic signal induced by channel processes. Lasting for $6 \mathrm{~h}$, the seismically recorded channel activity is likely to have included bedload-transporting flows as well as debris flows, both of which can be registered by the warning system (Badoux et al., 2009).

Away from the channel, stations like IGB05 did not exhibit such long period activity (Fig. 2). During the convective rainstorm, they recorded discrete bursts of high-frequency seismic energy $(>1 \mathrm{~Hz})$ lasting several tens of seconds. On seismograms, these events have short, impulsive peaks associated with multiple sources located at or near the surface. These characteristics are common for rockfalls and rock avalanches (Deparis et al., 2008; Helmstetter and Garambois, 2010; Dammeier et al., 2011). The potential increase of highfrequency seismic energy induced by the channel activity may prevent detecting the rockfall activity (Burtin et al., 2013). However, the stations deployed around the catchment, like IGB05, are not affected by such a source. Indeed, in contrast to other locations like the Himalayas (Burtin et al., 2008) or Taiwan (Hsu et al., 2011), the Illgraben channel has a limited extent, which reduces its capacity to produce an elevated background seismic noise. Therefore, the possible occurrence of a debris flow does not alter our ability to detect a significant slope activity.

High-frequency seismic signals can also have an anthropogenic origin (McNamara and Bulland, 2004). However, short-duration human disturbances in the Illgraben catchment were mainly restricted to the occasional passage of hikers, whose signals are only recorded over distances of tens of metres from a station. Noise from traffic, construction and gravel mining at the periphery of the Illgraben array was limited to a specific, narrow frequency band [2-4] Hz (Fig. 2b) and for the seismic stations deployed on the debris fan. Shortduration anthropogenic signals were not typically recorded at multiple stations in the Illgraben. In contrast, hillslope processes with larger magnitudes were observed by the entire seismic array. Such hillslope events were well expressed in 


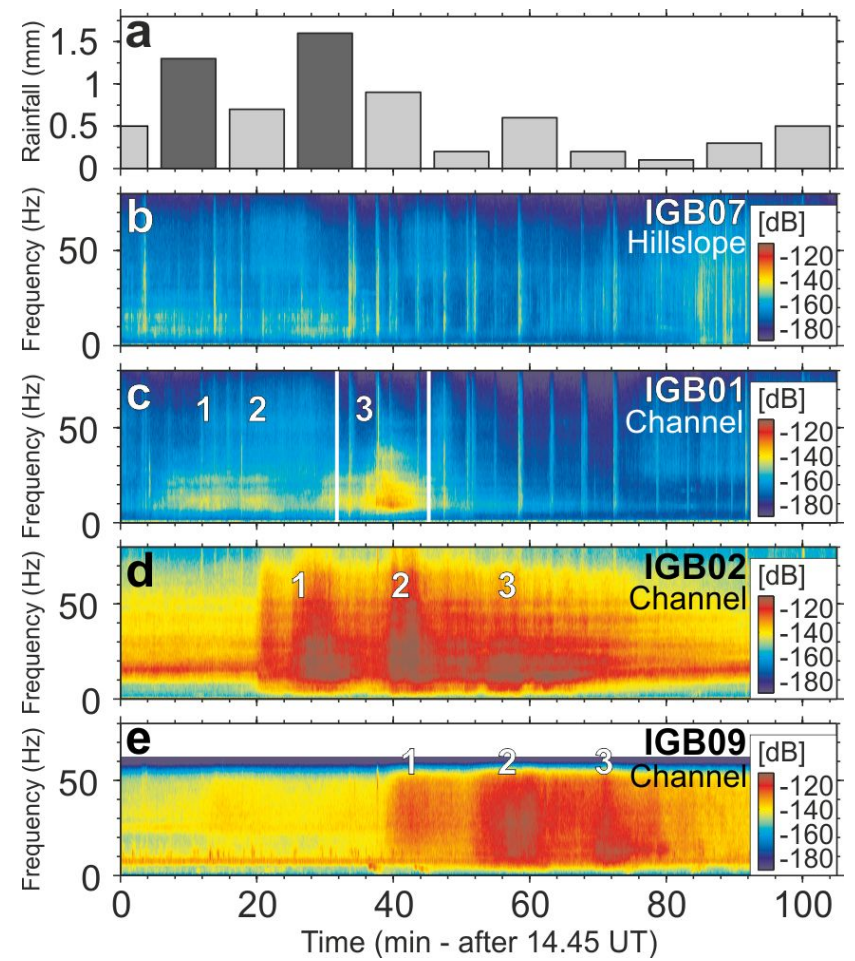

Figure 3. Seismic records of principal geomorphic activity in the Illgraben associated with rainfall on July 13, 2011. (a) Mean of 10 min rainfall intensity recorded at stations ILL2 and ILL3, inside the Illgraben (see Fig. 1). (b-e) Spectrograms in decibel of the vertical seismic signal at stations IGB07 (b), IGB01 (c), IGB02 (d) and IGB09 (e). Note the downstream propagation of seismic energy pulses 1-3. Propagation velocities ranged from $1.0-4.5 \mathrm{~m} \mathrm{~s}^{-1}$. Vertical white lines on (c) delimit the time span of Fig. 4.

the spectrograms of stations IGB01 and IGB07 (Fig. 3), located inside and at the high western periphery of the catchment, respectively. For the day of study, two local earthquakes were reported by the Swiss Seismological Service (SED). They both occurred in the morning at 04:30:59 UTC (Ml 0.7) and 05:56:24 UTC (Ml 1.2) at distances of $20 \mathrm{~km}$ and $28 \mathrm{~km}$ from the Illgraben catchment, respectively. Therefore, we can exclude local tectonic events as potential sources of the signals we recorded and as triggers of surface processes during the rainstorm.

\subsection{Seismic anatomy of a debris flow sequence}

Focusing on the flow sequence starting at 15:15 UTC, stations along the channel recorded seismic activity with a broad high-frequency content $([1-50] \mathrm{Hz})$ that occurred in three main episodes (pulses 1-3, Fig. 3). Lasting about $10 \mathrm{~min}$ each, these seismic energy pulses were timed progressively later at consecutive stations along the channel, showing the downstream propagation of their source. The coincidence between the occurrence of these propagating seismic pulses and debris flows reported by the warning system in the Illgraben
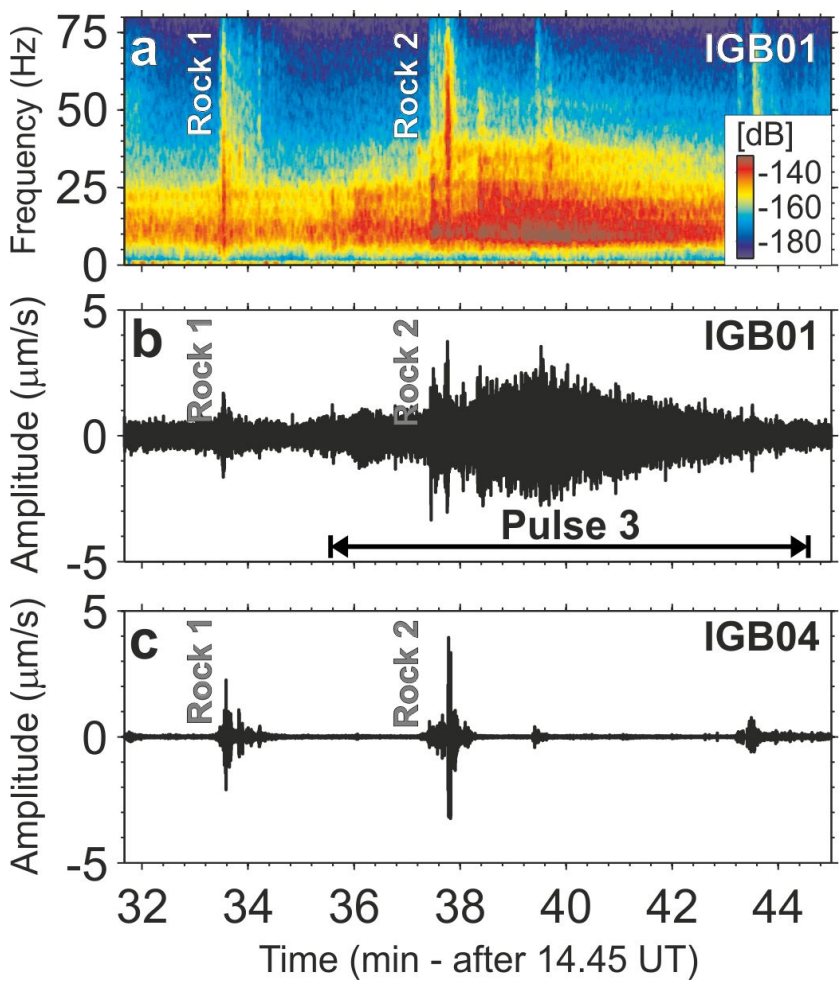

Figure 4. Linked mass wasting and channel flow in the upper Illgraben during flow pulse 3. (a) Spectrogram of the vertical seismic signal at station IGB01 during the flow pulse 3. The seismic energy is given in decibel relative to the velocity. Two rock avalanches (rocks 1 and 2) caused a short, sharp increase of the seismic energy at high-frequency $(>1 \mathrm{~Hz})$. The gradual increase of the seismic energy over the time interval shown here reflects the increase of channel activity and the approach and passage of a flow pulse. (b-c) Vertical [1-50] Hz bandpass filtered seismograms at stations IGB01 (b) and IGB04 (c). Note the absence of channel-induced seismic signals at station IGB04 and the prominence of signals from rockfalls 1 and 2 at both stations.

channel implies a link between them and we propose that the mobile seismic pulses represent the downstream propagation of three flow events. Furthermore, detailed analysis of the structure of these episodes reveals that at station IGB01, high on the central channel (Fig. 3c), the initial flow pulse had a gradual onset and was not clearly separated from the second pulse, even though they were so further downstream. In the upper Illgraben, the third flow pulse had a distinct and stronger seismic signal. Notably, this flow pulse was preceded by a short duration signal with rockfall characteristics, which was recorded at most stations (rock 1 at $\sim 33 \mathrm{~min}$, Fig. 4). The location of this event is key to understanding its possible connection to the third flow pulse.

Applying our location approach to the rock 1 event, we found that it occurred in the steep rock wall constituting the western flank of the catchment at an elevation of 1400 $1900 \mathrm{~m}$ and within a $200 \times 700 \mathrm{~m}$ area of uncertainty (Fig. 5). 

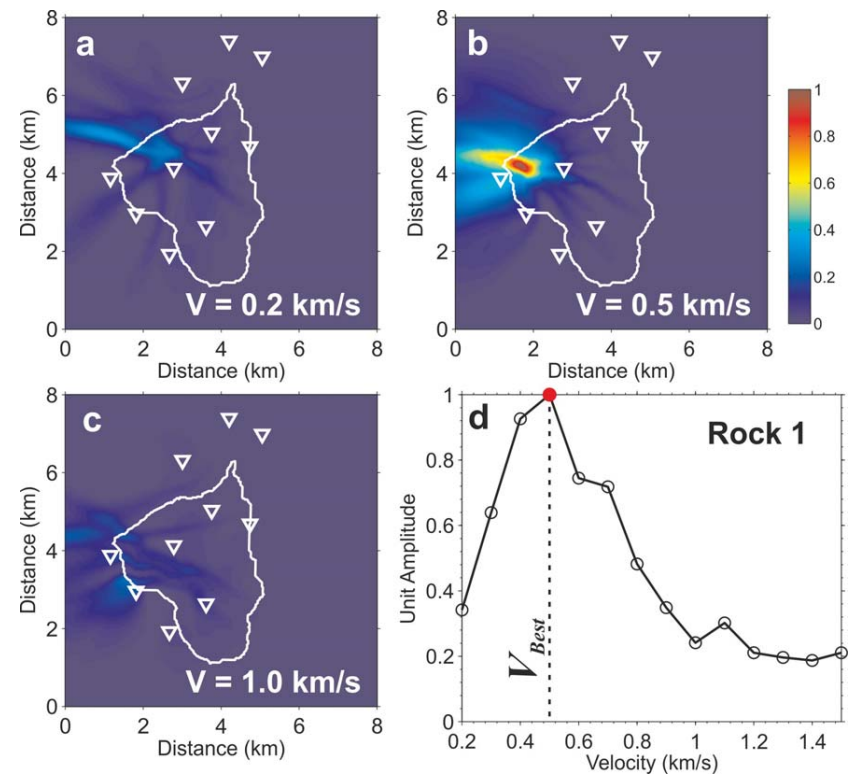

Figure 5. Location of mass wasting events in the Illgraben. (a-c) Probability density map (unit amplitude) for rock 1 location in the [29-29.5] Hz frequency band. Migration velocities are 0.2 (a), 0.5 (b) and $1.0 \mathrm{~km} \mathrm{~s}^{-1}$ (c). (d) Migration velocity analysis where the maximum amplitude corresponds to the best fit propagation velocity $\left(0.5 \mathrm{~km} \mathrm{~s}^{-1}\right.$ for rock 1$)$.

The best-fit velocity for location of this event is $0.5 \mathrm{~km} \mathrm{~s}^{-1}$, which is realistic for the propagation of shear or surface waves at shallow depths. The likely source area of rockfall rock 1 is connected to the uppermost section of the Illgraben channel, about $720 \mathrm{~m}$ upstream of station IGB01 (Fig. 6a). After a delay of about $160 \mathrm{~s}$, an increase of seismic energy was observed at station IGB01, suggesting that rock 1 may have triggered flow pulse 3 . The delay may reflect the time needed for the rockfall debris to become embedded within a channel flow and for that flow to arrive near IGB01.

During transit of flow pulse 3, a further significant, short duration event was detected at multiple stations (rock 2 at $\sim 37 \mathrm{~min}$, Fig. 4). This rockfall was located adjacent to the Illgraben channel, within a $400 \times 750 \mathrm{~m}$ area of uncertainty, about $650 \mathrm{~m}$ downstream of station IGB01 (Fig. 6a). The best-fit velocity for location of this second avalanche is $0.6 \mathrm{~km} \mathrm{~s}^{-1}$, which is consistent with the best-fit velocity for rock 1 . This event may have been caused by ground vibrations or bank erosion during the passage of the sedimentladen flow pulse, and resulted in an immediate and sustained increase of $5 \% \mathrm{~dB}$ in the [9-12] Hz seismic energy recorded at station IGB01. We attribute this increase to a sudden addition of sediment to the flow. Thus, our seismic data suggest that an effective, two-way link exists between the Illgraben channel and the surrounding hillslopes, whereby mass wasting during rainstorms can cause the constitution of a flow capable of transporting significant amounts of sediment, and this flow in turn can induce further mass wasting during pas-
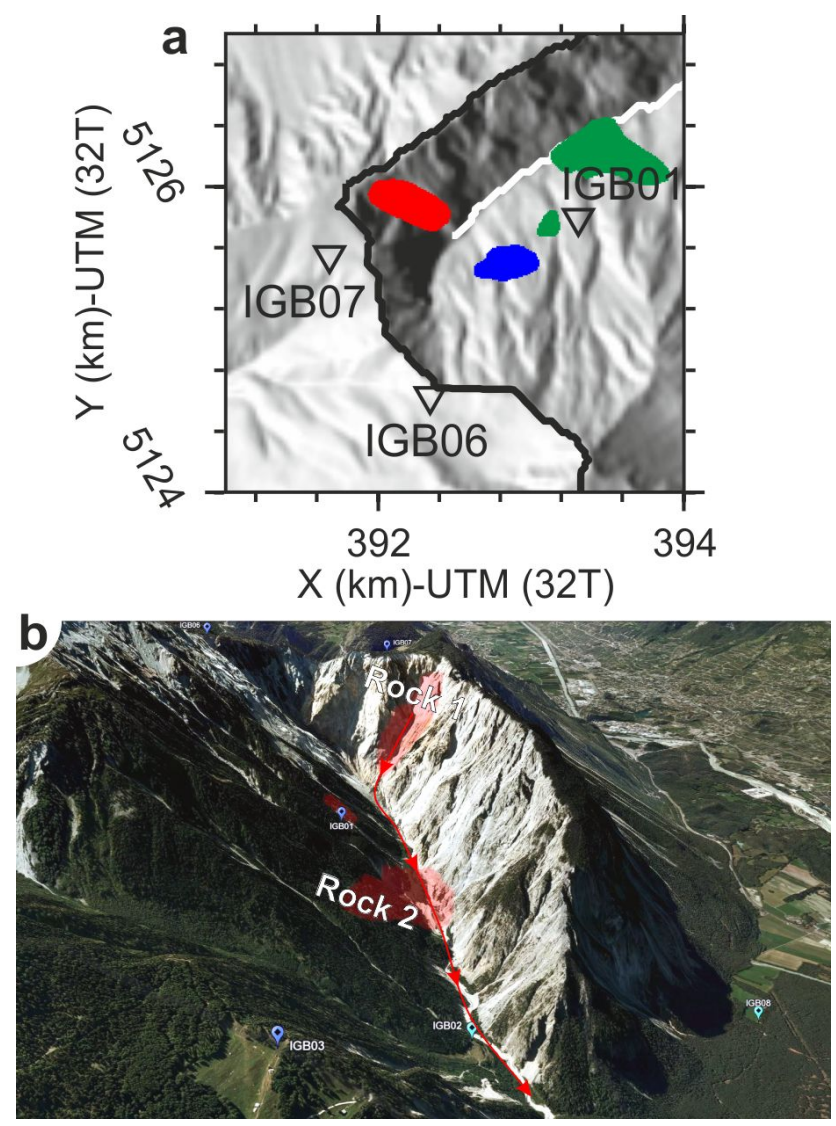

Figure 6. Location of hillslope events. (a) The likely location of mass wasting events related to pulse 3 : rock 1 (red), rock 2 (green) and pulse 2 trigger event rock 0 (blue), all shown on a relief map of the Illgraben catchment. The colour patches indicate areas of equal probability for the event locations that correspond to the upper $75 \%$ of the dynamic range from the event probability density maps (Fig. 4). Events located upstream stand on large, active gullies connected with the main stream. (b) Locations of rock avalanches (rocks 1 and 2), shown with the pathway of the flow pulse 3 with which they were associated (red curve). This series of events illustrates the two-way link between channel and slope domains.

sage (Fig. 6). Independent evidence for the occurrence and location of the seismically detected rockfalls in this sequence does not exist. However, the initiation zone coincides with active slopes in which rock avalanches have been observed previously, including a $3-5 \times 10^{6} \mathrm{~m}^{3}$ rock avalanche in 1961 (Gabus et al., 2008; Bennett et al., 2013).

Observations on the other two flow pulses and further rockfalls that occurred during the same storm indicate that the connections between hillslope and channel processes and their role in the initiation of flow events in the Illgraben channel are diverse. Flow pulse 2 may have started in a similar way to flow pulse 3 , with a rockfall (rock 0 ) detected in the southeast flank of the catchment (Fig. 6), in a slope known to be very active (Bennett et al., 2012). In contrast, flow pulse 1 was not directly associated with marked rockfall activity. 


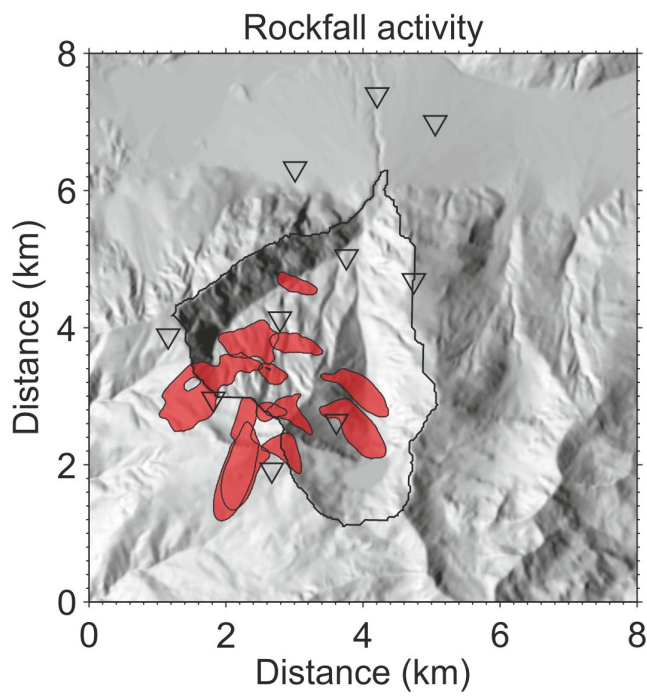

Figure 7. Location of seismic events during the convective rainstorm of 13 July 2011. The most likely area of initiation $(>0.75$ of the dynamic range of the probability density function) for each event is represented in red. The station locations are indicated in inverse triangles. In contrast to rock 1 and rock 2 , this slope activity cannot be associated with the initiation or downstream propagation of three flow pulses observed in the main Illgraben channel during the storm.

Instead, erosion of sediment from the headwater channel bed after sufficient runoff had accumulated may have caused this pulse. Neither flow pulse 1 nor 2 triggered any obvious secondary mass wasting during passage, but many other highfrequency short duration events were observed at most stations (Fig. 3). To locate these events, we applied the procedure also used for events rocks $0-2$. In all, we managed to locate 12 further high-frequency short duration events. Within the bounds of uncertainty $(>0.75$ of the dynamic range of the probability density function), most of them occurred within the Illgraben catchment (Fig. 7), many in the southeast flank, where intense erosion had been observed in previous years (Bennett et al., 2012). With temporal and frequency characteristics of rockfall events and in view of their spatial distribution in the Illgraben catchment, we have interpreted these events as rockfalls triggered by rainfall. One such event occurred in the immediate vicinity of the debris flow channel, close to the location of event rock 2 (Fig. 6), 38 min after the passage of the last flow pulse. This event may have been a bank collapse, involving colluvium exposed in the channel flank, after the passage of multiple flow pulses. All other detected rockfalls occurred without evident connection with channel processes. This illustrates the complexity of the coupling of slope and channel processes and the diversity of mechanisms by which debris flows can arise in the Illgraben.

\section{Channel Dynamics}

\subsection{Flow propagation velocity}

Having considered mass wasting in the steep flanks of the Illgraben, we now turn to activity in the central channel of the catchment. The link between pulses of seismic energy recorded at stream-side stations and the flow propagation in the Illgraben channel can be used to infer some characteristics of the channel dynamics. To do this, we tracked the downstream progress and evolution of the three flow pulses with seismic data from stations IGB01, IGB02 and IGB09, located closest to the channel (Fig. 1). The propagation velocity of flow pulses in the Illgraben channel was estimated from the envelopes of seismic energy recorded along the main stream. Prior to computing the seismic envelopes, we bandpass filtered the seismic signals of each component (vertical, north and east) between 5 and $20 \mathrm{~Hz}$. We then averaged the three components of a station, and the passage of a pulse was assumed to coincide with the peak amplitude of the seismic envelopes at a station. Distances along the Illgraben channel were measured directly from ortho-rectified aerial photographs. For pulses 1 and 2, we fixed the start of propagation to match the pulse arrival at station IGB01. Flow pulse 3 is assumed to have started at the location and time of rockfall rock 1.

Seismically determined flow velocities ranged from 1.0 $4.5 \mathrm{~m} \mathrm{~s}^{-1}$ and are within the range of measured debris flow velocities in the channel $\left(0.8-7 \mathrm{~m} \mathrm{~s}^{-1}\right)$ (Badoux et al., 2009). The propagation velocity showed some spatial variations with lower values of $\sim 1 \mathrm{~m} \mathrm{~s}^{-1}$ inside the catchment (between IGB01 and IGB02) than on the debris fan $\left(\sim 4 \mathrm{~m} \mathrm{~s}^{-1}\right.$, Fig. 8 and Table S3). This observation may indicate that the effects of channel roughness dominated over those of channel slope in setting flow velocity. In contrast to this spatial pattern, the temporal variations were limited and the three flow pulses had similar velocity signatures.

\subsection{Flow seismic energy}

Despite the similarities in flow velocity, the energy level of seismic signals evolved between channel stations and differed between flow pulses (Fig. 8b). To properly compare station observations recorded at different distances from potential sources, in this case the stream, a first-order correction of the seismic energy must be applied, accounting for the geometrical spreading of seismic waves (e.g. Aki and Richards, 1980). We estimated the seismic energy along the main channel by power spectral density analysis and corrected for the travelled distance between a station and the channel as follows. For each station and each flow pulse, we computed the average seismic energy in the [5-20] Hz frequency band and in a $\pm 30 \mathrm{~s}$ time window around the peak amplitude observed during passage of the pulse. The uncertainty on this estimate 

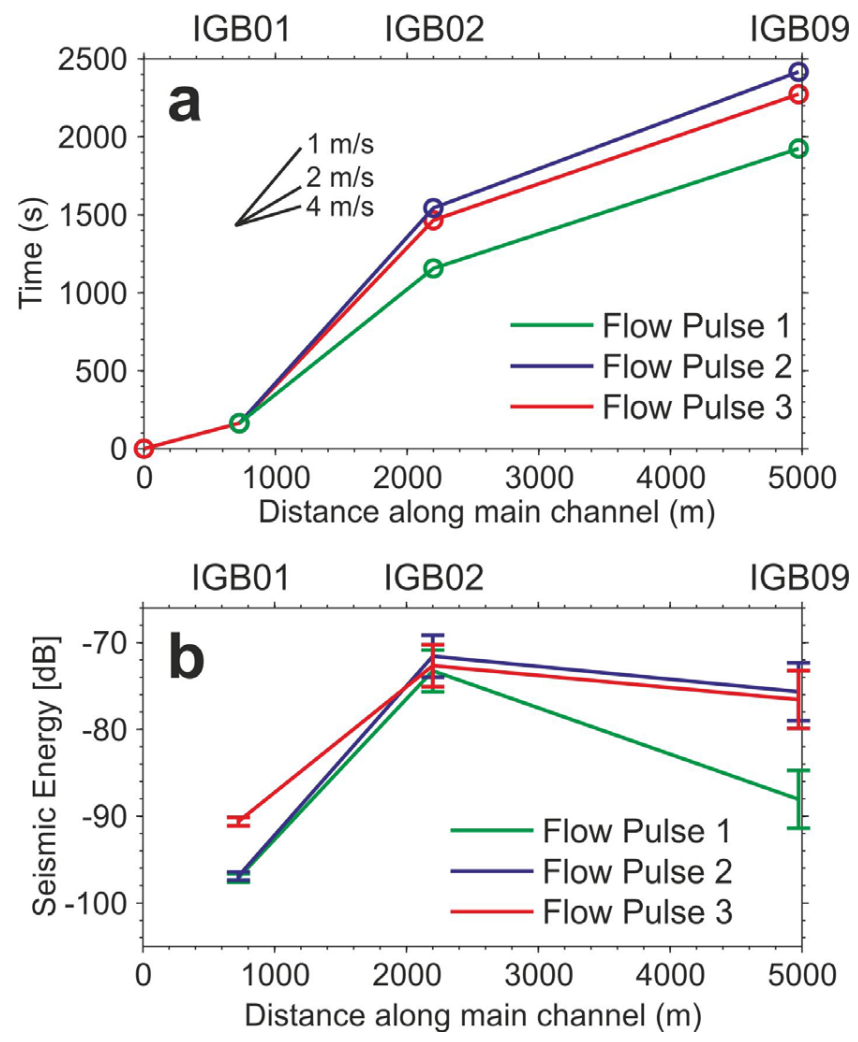

Figure 8. Velocity and energy characteristics of the debris flow sequence. (a) Downstream propagation of the three main flow pulses. The propagation is defined with the recordings of seismic envelopes at side-stream stations IGB01, IGB02 and IGB09. (b) Mean seismic energy of each flow pulse recorded at the same stations. The amplitude in decibel is corrected for the geometrical spreading of body waves.

was defined as the standard deviation from the mean seismic energy.

Taking the Illgraben channel as the principal source of energy, we calculated the average distance $R$ from a station to the nearest $250 \mathrm{~m}$ stream segment. We applied this value to correct the seismic energy according to the propagation of body waves $\left(\sim 1 / R^{2}\right)$ because the channel stations are relatively close to the potential seismic sources and the travelled ray paths can be assumed to be relatively uniform in the near field. The largest distance to the channel was $432 \mathrm{~m}$, at station IGB01. Stations IGB02 and IGB09 had an equal distance to stream of $121 \mathrm{~m}$, making it possible to compare these two stations without correction. A geometrical spreading correction that would apply to surface waves would not lead to drastic changes in the observed trends. Naturally, a full correction should also consider the anelastic properties of the medium that account for the frequency dependence of wave attenuation. However, in the absence of an estimate of quality factors and an attenuation law, we did not attempt this correction. For a first order estimate of the energy, the correction for geometrical spreading and uniform anelastic medium properties has to suffice at present. Hence, we do not interpret the absolute seismic energy, but instead associate the relative changes along the channel to the erosion, transfer and deposition of sediments. For the quantification of these channel processes, a careful analysis of the seismic wave content must be carried out to properly interpret the seismic energy, which is outside the scope of this study.

According to our observations, the seismic energy of all three flow pulses increased by $30-35 \%$ dB between IGB01 and IGB02, inside the Illgraben catchment. In contrast, on the debris fan between IGB02 and IGB09, the energy decreased by $18 \% \mathrm{~dB}$ for flow pulse 1 , and only by $5 \% \mathrm{~dB}$ for the flow pulses 2 and 3 (Fig. 8b). These variations reflect the evolution of the flows along the channel, perhaps indicating changes in the frictional characteristics of flood flows or an increase of flow discharge due to erosion or decrease in discharge due to deposition, both of which have been documented on the fan of the Illgraben (Schürch et al. 2011; Berger et al., 2011) for debris flows and debris floods.

\subsection{Comparison with in situ monitoring}

A comparison of the recorded seismic signals of the flow pulses with data from in situ stream monitoring yields further information about the flow properties and their evolution. For this purpose, we used data on flow depth and particle impact rate from check dam 29 (CD29, Fig. 1), located 400 m downstream of station IGB09. This distance implies a time delay between observations of flow pulses in the seismic data and flow depth and impact rate data. Moreover, a seismic sensor detects approaching flows before they reach the in-channel location nearest the station, giving rise to a progressive increase of registered seismic energy. In contrast, passage of a steep-fronted flow is registered as a sudden increase of flow depth at CD29. Acknowledging these differences, we compare the flow characteristics inferred from seismic and instream observations.

The spectrograms at near-channel stations showed notable shifts in the frequency content of signals and variations of seismic energy during the sequence of flow pulses (Fig. 3). At station IGB09, flow pulse 1 had relatively little seismic energy below $15 \mathrm{~Hz}$, whereas pulses 2 and 3 had more energy at lower frequencies and greater seismic amplitudes (Fig. 9). In contrast, the flow depth at CD29 was similar for pulses 1 and 2 (Fig. 9c), and it peaked between pulses 2 and 3 when the seismic energy reached a temporary low (between 65 and 70 min, Fig. 9b). In addition, the flow depth of pulse 3 was relatively small, $45 \%$ below the peak value, whereas seismic amplitude increased by $130 \%$ for the same period. These comparisons indicate that there is no direct relation between seismic signals and the flow level, and that other flow attributes might be involved.

Bedload sediment transport is a likely source of seismic energy, which can be independently tracked from records of bedload impact rate. Flow pulse 1 had a relatively low 
bedload impact rate, 20 times less than flow pulse 2, even though these flows had similar depths and velocities (Figs. 9d and 8a, respectively). Meanwhile, the seismic amplitude increased by $215 \%$ at IGB09 from flow pulse 1 to flow pulse 2. Flow pulse 3 had a moderate seismic amplitude and bedload activity. Thus, the recorded seismic amplitudes are in qualitative agreement with bedload observations rather than with flow depth. However, a clear relation between seismic amplitude and bedload impact rate is difficult to define because it is likely to be prone to grain size effects on the frequency content of the seismic signal. Moreover, the duration of a flow pulse can influence the seismic energy delivered in the streambed. A sharp, strong seismic peak can have a total energy equivalent to that of a long and smooth seismic pulse. Along the $4.25 \mathrm{~km}$ channel reach between IGB01 and IGB09, the three flow pulses had a similar seismic duration of $11 \mathrm{~min}( \pm 104 \mathrm{~s})$, with limited fluctuations of 5, 16 and $14 \%$ (standard deviation) for pulses 1, 2 and 3, respectively (Fig. S4). Therefore, possible effects of stretching in time of the flow pulses can be discarded. The video camera located at CD29 recorded the passage of the debris-flow sequence. With a sampling rate of one picture per second, we noticed an elevation of flow level, as indicated by the flow height data set (Fig. 9c), but we could not extract additional information that could help to decipher the bedload fluctuation as shown by the impact rate data set (Fig. 9d).

If bedload transport has a dominant contribution to the seismic energy recorded along the Illgraben main stream, then the frequency pattern of the seismic signal should reflect an addition or loss of large sediment particles in the flow because large sediment particles produce lower frequency signals than small particles (Huang et al., 2007). At IGB09, flow pulse 1 had the lowest amplitude and little seismic energy below $15 \mathrm{~Hz}$. These observations indicate a paucity of coarse bedload in the flow, which agrees with the fact that this flow pulse had low bedload impact rates at CD29 despite its relatively large discharge. Notably, pulse 1 underwent a strong reduction of seismic energy $(18 \% \mathrm{~dB})$ across the fan, where the channel bed gradient decreases from 16 to $10 \%$, likely reflecting progressive deposition of sediment in the lower channel reach. This may have affected the coarsest sediment fraction in the first instance, explaining the subdued seismic activity in the channel on the distal part of the fan.

Despite a similar flow depth to flow pulse 1, flow pulse 2 had the highest seismic amplitude, with significant signal at frequencies below $15 \mathrm{~Hz}$ at station IGB09. Comparison of the seismic signal envelopes at IGB02 and IGB09 in the debris fan confirms the decay of amplitude for flow 1, whereas flow 2 remains the highest peak of the sequence (Fig. S4bc). We attribute this to a greater sediment concentration and a high transport rate of coarse bedload in flow pulse 2 . The increase of seismic energy, indicating higher impact energy, during pulse 2 highlights a higher potential for channel bed abrasion at the base of this denser flow. For pulse 3, the interpretation of available data is less straightforward. This pulse
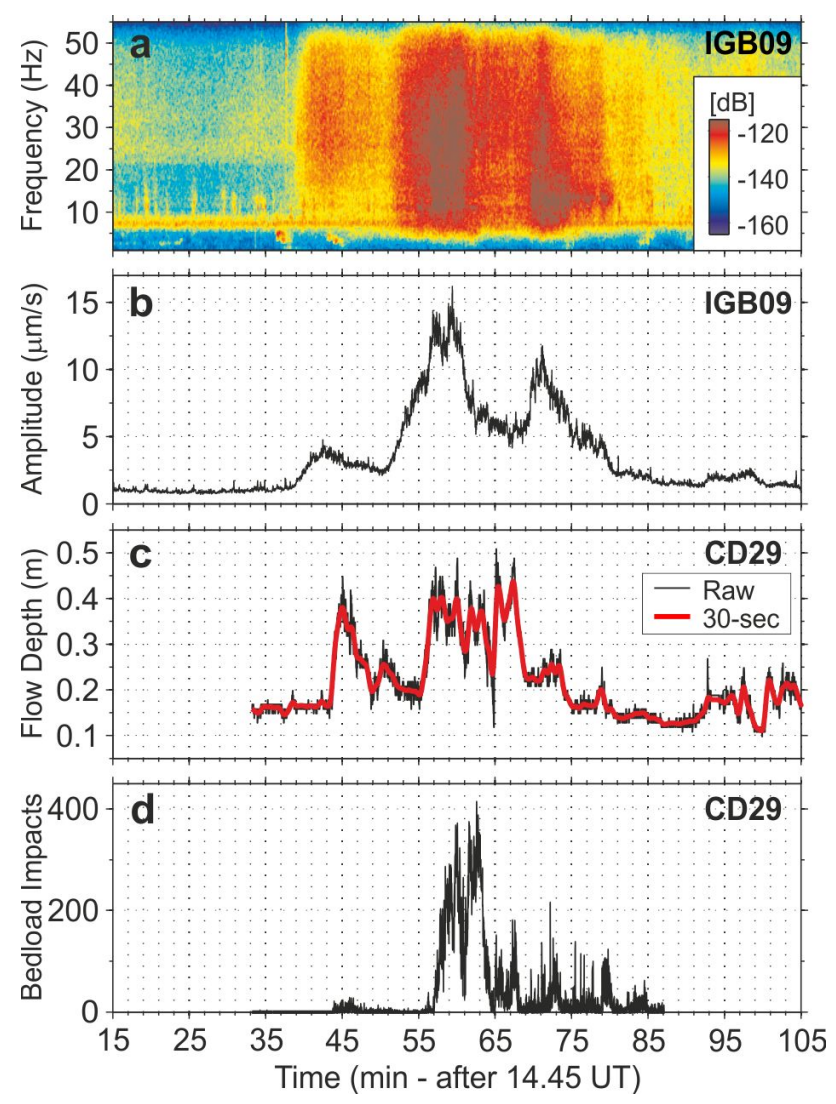

Figure 9. Flow pulse characteristics on the distal fan. (a) Spectrogram in decibel of the vertical seismic signal at station IGB09 during passage of flow pulses 1-3. (b) [5-50] Hz vertical seismic envelop at IGB09 showing three flow pulses. (c) Raw (black line) and $30 \mathrm{~s}$ smoothed (red line) flow depth data recorded at CD29, $400 \mathrm{~m}$ downstream of IGB09 (2 min at established flow speed). (d) Bedload impact rates recorded at CD29.

had the second highest seismic amplitude of the main flow sequence on this day with a substantial signal below $15 \mathrm{~Hz}$, reflecting a substantial bedload transport rate. However, the pulse had only a limited flow depth and moderate bedload impact rates. Lower than expected impact rates may have resulted from a debris flow with different internal organization of the bedload material and/or from the way in which sediment particle impacts are recorded. This is done with force plates, which register an impact only when its force or acoustic amplitude (geophone) exceeds a pre-defined threshold. The absolute amplitude of such impacts is not recorded. Since the flow depth of pulse 3 was small, sediment particles may have had less energy at impact due to low drop heights and particle velocities, which could explain both reduced impact rates at CD29 and moderate seismic energy at IGB09. 


\section{Conclusions}

Geomorphic processes generate seismic signals with distinct and different characteristics in the amplitude- and frequencytime domains, reflecting their mechanisms, granulometry, timing, location and velocity. Recording such signals with a two-dimensional seismological array, we have mapped the spatiotemporal patterns of geomorphic activity in the Swiss Illgraben, a steep mountain catchment with high erosion rates. Our array consisted of stations deployed around the catchment and along the main channel, allowing recognition, location and tracking of rockfalls on slopes as well as flow pulses in the central channel and revealing the links between individual processes. This has been done for a single convective storm.

During this storm on 13 July 2011, three separate flow pulses occurred within the Illgraben main channel, each with a significant sediment load and with the characteristics of a debris flow for at least part of the surveyed channel length. These pulses did not have common starting conditions, either in terms of precipitation, or in terms of the trigger mechanism. The first flow pulse started without detected precursor activity on catchment hillslopes, instead mobilizing sediment already present in the channel. In contrast, the other two pulses were triggered by rockfalls in the steep headwater slopes. Within the Illgraben catchment, we noticed a systematic energy increase along the bedrock channel, presumably in response to the entrainment of channel bed material (pulse 1) and/or hillslope inputs (pulses 2 and 3). During pulse 3, passage of the flow appeared to trigger a secondary mass wasting event on an adjacent hillslope. On the debris fan, pulse 1 underwent a decrease of seismic energy, whereas pulses 2 and 3 maintained their high level of energy. These trends may reflect changes in the sediment load of the propagating flows. The seismic records and independently measured particle impact rates suggest that pulse 1 had a diminished coarse sediment load, possibly causing change from a debris flow into a hyper-concentrated flow on the lower part of the debris fan. Pulses 2 and 3 maintained their energy and thus their character across the fan. Thus, our seismic observations suggest that within the time span of a single convective rainstorm, dynamic links exist between a channel and the adjacent hillslopes that can determine the onset and evolution of bedload transport in mountain catchments, and that sediment erosion and deposition during downstream propagation of these flows affect their density and rheology, and likely also their potential for erosion by particle impacts.

By recording frequency-specific amplitude information, seismic instruments register at distance many aspects of flow processes that can be confirmed with in situ observations from force plates. For many hillslope processes, such as rockfalls, quantitative in situ observation is disproportionately more difficult, and seismic records may provide insights into their mechanisms that are hard to obtain in other ways. Moreover, this seismological approach is effective on the land- scape scale. The ensemble of seismic observations, made on individual, naturally occurring geomorphic process events that are tracked from inception to near termination, can reveal the ways in which separate landscape elements interact under specific meteorological conditions and how geomorphic events are constituted by multiple surface process manifestations with causal links. Thus, seismology, pursued with twodimensional instrument networks, makes it possible for the first time to monitor distributed surface process activity with sufficient spatial as well as temporal resolution to observe and constrain the dynamics of erosional landscapes.

With telemetry and automated analysis of seismic data, this approach may give significant early warning capabilities in settings where natural hazard monitoring is now limited to localized downstream observations. Finally, combined seismological and meteorological monitoring of upland catchments over multiple annual cycles stands to yield fundamental, quantitative constraints on the role of weather as a driver of erosion and insights into the role of climate and climate change in landscape evolution. Such long-term surveys should include independent constrains on slope activity, like laser scanning, to verify locations of erosion and deposition and to calibrate the conversion from measured seismic energy to mass of rock or sediment displaced. This conversion is essential to achieving the goal of knowing the timing and location of geomorphic events in a landscape and how much material is involved.

\section{Supplementary material related to this article is available online at http://www.earth-surf-dynam.net/2/ 21/2014/esurf-2-21-2014-supplement.pdf.}

Acknowledgements. This study was supported by the AXA Research Fund and the Isaac Newton Trust of the University of Cambridge. We thank the SEIS-UK equipment pool (NERC) and the École et Observatoire des Sciences de la Terre of Strasbourg for providing the seismic instruments, the WSL for logistic support and M. Raymond Pralong, K. Steiner, N. Federspiel, T. Glassey and F. Dufour for help in the field. Thanks are also due to A. Helmstetter, M. Attal, L. Hsu and the associate editor J. Braun for their comments and suggestions, which have improved the clarity of the paper.

The service charges for this open access publication have been covered by a Research Centre of the Helmholtz Association.

Edited by: J. Braun

\section{References}

Aki, K. and Richards, P. G.: Quantitative Seismology: Theory and Methods, University Science Books, 2002, ISBN 978-1-89138963-4, 700 pp., 2002. 
Arattano, M. and Marchi, L.: Systems and sensors for debrisflow monitoring and warning, Sensors, 8, 2436-2452, doi:10.3390s8042436, 2008.

Attal, M. and Lavé, J.: Changes of bedload characteristics along the Marsyandi River (central Nepal): Implications for understanding hillslope sediment supply, sediment load evolution along fluvial networks, and denudation in active orogenic belts, edited by: Willett, S. D., Hovius, N., Brandon, M. T., and Fisher, D., Spec. Pap. Geol. Soc. Am., 398, 143-171, 2006.

Attal, M., Tucker, G. E., Whittaker, A. C., Cowie, P. A., and Roberts, G. P.: Modeling fluvial incision and transient landscape evolution: Influence of dynamic channel adjustment, J. Geophys. Res., 113, F03013, doi:10.1029/2007JF000893, 2008.

Badoux, A., Graf, C., Rhyner, J., Kuntner, R., and McArdell, B. W.: A debris-flow alarm system for the Alpine Illgraben catchment: design and performance, Nat. Hazards, 49, 517-539, 2009.

Bennett, G. L., Molnar, P., Eisenbeiss, H., and McArdell, B. W.: Erosional power in the Swiss Alps: characterization of slope failure in the Illgraben, Earth Surf. Process. Landforms, 37, 16271640, doi:10.1002/esp.3263, 2012.

Bennett, G. L., Molnar, P., McArdell, B. W., Schlunegger, F., and Burlando, P.: Patterns and controls of sediment production, transfer and yield in the Illgraben, Geomorphology 188, 68-82, 2013.

Berger, C., McArdell, B. W., and Schlunegger, F.: Direct measurement of channel erosion by debris flows, Illgraben, Switzerland, J. Geophys. Res., 116, F01002, doi:10.1029/2010JF001722, 2011.

Brodsky, E. E., Kanamori, H., and Sturtevant, B.: A seismically constrained mass discharge rate for the initiation of the May 18, 1980 Mount St. Helens eruption, J. Geophys. Res., 104, 29, 387-29, 1999.

Burbank, D. W., Leland, J., Fielding, E., Anderson, R. S., Brozovic, N., Reid, M. R., and Duncan, C.: Bedrock incision, rock uplift and threshold hillslopes in the northwestern Himalayas, Nature, 379, 505-510, 1996.

Burtin, A., Bollinger, L., Vergne, J., Cattin, R., and Nábělek, J. L.: Spectral analysis of seismic noise induced by rivers: A new tool to monitor spatiotemporal changes in stream hydrodynamics, J. Geophys. Res., 113, B05301, doi:10.1029/2007JB005034, 2008.

Burtin, A., Bollinger, L., Cattin, R., Vergne, J., and Nábělek, J. L.: Spatiotemporal sequence of Himalayan debris flow from analysis of high-frequency seismic noise, J. Geophys. Res., 114, F04009, doi:10.1029/2008JF001198, 2009.

Burtin, A., Vergne, J., Rivera, L., and Dubernet, P.-P.: Location of river induced seismic signal from noise correlation functions, Geophys. J. Int., 182, 1161-1173, 2010.

Burtin, A., Cattin, R., Bollinger, L., Vergne, J., Steer, P., Robert, A., Findling, N., and Tiberi, C.: Towards the hydrologic and bed load monitoring from high-frequency seismic noise in a braided river: the "torrent de St Pierre", French Alps, J. Hydrol., 408, 43-53, 2011.

Burtin, A., Hovius, N., Milodowski, D. T., Chen, Y.-G., Wu, Y.-M., Lin, C.-W., Chen, H., Emberson, R., and Leu, P.-L.: Continuous catchment-scale monitoring of geomorphic processes with a 2-D seismological array, J. Geophys. Res., 118, 1956-1974, doi:10.1002/jgrf.20137, 2013.

Cook, K. L., Turowski, J. M., and Hovius, N.: A demonstration of the importance of bedload transport for fluvial bedrock erosion and knickpoint propagation, Earth Surf. Process. Landforms, 38, 683-695, doi:10.1002/esp.3313, 2013.

Dammeier, F., Moore, J. R., Haslinger, F., and Loew, S.: Characterization of alpine rockslides using statistical analysis of seismic signals, J. Geophys. Res., 116, F04024, doi:10.1029/2011JF002037, 2011.

Deparis, J., Jongmans, D., Cotton, F., Baillet, L., Thouvenot, F., and Hantz, D.: Analysis of rock-fall and rock-fall avalanche seismograms in the French Alps, Bull. Seismol. Soc. Am., 98, 17811796, 2008.

Densmore, A. L., Anderson, R. S., McAdoo, B. G., and Ellis, M. A.: Hillslope evolution by bedrock landslides, Science, 275, 369372, 1997.

Favreau, P., Mangeney, A., Lucas, A., Crosta, G., and Bouchut, F.: Numerical modeling of landquakes, Geophys. Res. Lett., 37, L15305, doi:10.1029/2010GL043512, 2010.

Gabus J. H., Weidmann, M., Bugnon P.-C., Burri, M., Sartori, M., and Marthaler, M.: Geological Map of Sierre 1:25 000 (LK 1278, sheet 111), In Geological Atlas of Switzerland. Swiss Geological Survey: Wabern, Switzerland, 2008,

Govi, M., Maraga, F., and Moia, F.: Seismic detectors for continuous bed load monitoring in a gravel stream, Hydrol. Sci. J., 38, 123-132, 1993.

Hartshorn, K., Hovius, N., Dade, W. B., and Slingerland, R. L.: Climate-driven bedrock incision in an active mountain belt, Science 297, 2036-2038, doi:10.1126 science.1075078, 2002.

Helmstetter, A. and Garambois, S.: Seismic monitoring of Séchilienne rockslide (French Alps): analysis of seismic signals and their correlation with rainfalls, J. Geophys. Res., 115, F03016, doi:10.1029/2009JF001532, 2010.

Hervas, J, Barredo, J. I., Rosin, P. L., Pasuto, A., Mantovani, F., and Silvano, S.: Monitoring landslides from optical remotely sensed imagery: the case history of Tessina landslide, Italy, Geomorphology, 54, 63-75, 2003.

Hovius, N., Stark, C. P., Chu, H.-T., and Lin, J.-C.: Supply and Removal of Sediment in a Landslide-Dominated Mountain Belt: Central Range, Taiwan, The Journal of Geology, 118, 73-89, doi:10.1086/314387, 2000.

Hsu, L., Finnegan, N. J., and Brodsky, E. E.: A seismic signature of river bedload transport during storm events, Geophys. Res. Lett., 38, L13407, doi:10.1029/2011GL047759, 2011.

Huang, C.-J., Yin, H.-Y., Chen, C.-Y., Yeh, C.-H., and Wang, C.-L.: Ground vibrations produced by rock motions and debris flows, J Geophys. Res., 112, F02014, doi:10.1029/2005JF000437, 2007.

Itakura, Y., Inaba, H., and Sawada, T.: A debris-flow monitoring devices and methods bibliography, Nat. Hazards Earth Syst. Sci., 5, 971-977, 2005.

Korup, O., Densmore, A. L., and Schlunegger, F.: The role of landslides in mountain range evolution, Geomorphology, 120, 77-90, 2010.

Lacroix, P. and Helmstetter, A.: Location of seismic signals associated with microearthquakes and rockfalls on the Séchilienne landslide, French Alps, Bull. Seismol. Soc. Am., 101, 341-353, 2011.

Lacroix, P., Grasso, J.-R., Roulle, J., Giraud, G., Goetz, D., Morin, S., and Helmstetter, A.: Monitoring of snow avalanches using a seismic array: Location, speed estimation, and relationships to meteorological variables, J. Geophys. Res., 117, F01034, doi:10.1029/2011JF002106, 2012. 
Lin, C.-W., Shieh, C.-L., Yuan, B.-D., Shieh, Y.-C., Liu, S.-H., and Lee, S. Y.: Impact of Chi-Chi earthquake on the occurrence of landslides and debris flows: example from the Chenyulan River watershed, Nantou, Taiwan, Engineering Geology, 71, 49-61, 2004.

McArdell, B. W., Bartelt, P., and Kowalski, J.: Field observations of basal forces and fluid pore pressure in a debris flow, Geophys. Res. Lett., 34, L07406, doi:10.1029/2006GL029183, 2007.

McNamara, D. E. and R. P. Buland: Ambient noise levels in the continental United States, Bull. Seismol. Soc. Am., 94, 15171527, 2004.

Page, M. J., Trustrum, N. A., and DeRose, R. C.: A high-resolution record of storm-induced erosion from lake sediments, New Zealand, J. Paleolimnol,, 11, 333-348, 1994.

Saba, S. B., van der Meijde, M., and van der Werff, H.: Spatiotemporal landslide detection for the 2005 Kashmir earthquake region, Geomorphology, 124, 17-25, 2010.

Schlunegger F., Badoux A., McArdell B. W., Gwerder C., Schnydrig D., Rieke-Zapp D., and Molnar P.: Limits of sediment transfer in an alpine debris-flow catchment, Illgraben, Switzerland, Quat. Sci. Rev., 28, 1097-1105, 2009.

Schlunegger, F., Norton, K., and Caduff, R.: Hillslope processes in temperate environments, in: Treatise in Geomorphology 3, edited by: Marston, R. and Stoffel, M., Mountain and Hillslope Geomorphology, Elsevier, London, 2012.

Schürch, P., Densmore, A. L., Rosser, N. J., and McArdell, B. W.: Dynamic controls on erosion and deposition on debris-flow fan, Geology, 39, 827-830, 2011.

Sklar, L. and Dietrich, W. E.: Sediment and rock strength controls on river incision into bedrock, Geology, 29, 1087-1090, 2001.
Snyder, N. P., Whipple, K. X., Tucker, G. E., and Merritts, D. J.: Landscape response to tectonic forcing: Digital elevation model analysis of stream profiles in the Mendocino triple junction region, northern California, Geol. Soc. Am. Bull., 112, 1250-1263, 2000.

Stark, C. P., Barbour, J. R., Hayakawa, Y. S., Hattanji, T., Hovius, N., Chen, H., Lin, C.-W., Horng, M.-J., Xu, K.-Q., and Fukahata, Y.: The climatic signature of incised river meanders, Science, 327, 1497-1501, 2010.

Thomson, D. J.: Spectrum estimation and harmonic analysis, Proc. IEEE, 70, 1055-1096, 1982.

Turowski, J. M., Lague, D., and Hovius, N.: Cover effect in bedrock abrasion: a new derivation and its implications for the modeling of bedrock channel morphology, J. Geophys. Res., 112, F04006, doi:10.1029/2006JF000697, 2007.

Whipple, K. X.: Bedrock Rivers and the Geomorphology of Active Orogens, Ann. Rev. Earth Planet. Sci., 32, 151-185, 2004.

Wobus, C. W., Tucker, G. E., and Anderson, R. S.: Does climate change create distinctive patterns of landscape incision?, J. Geophys. Res., 115, F04008, doi:10.1029/2009JF001562, 2010.

Yanites, B. J., Tucker, G. E., Hsu, H.-L., Chen, C., Chen, Y.G., and Mueller, K. J.: The influence of sediment cover variability on long-term river incision rates: An example from the Peikang River, central Taiwan, J. Geophys. Res., 116, F03016, doi:10.1029/2010JF001933, 2011.

Zhang, H., Nadeau, R. M., and Toksoz, M. N.: Locating nonvolcanic tremors beneath the San Andreas Fault using a stationpair double-difference location method, Geophys. Res. Lett., 37, L13304, doi:10.1029/2010GL043577, 2010. 